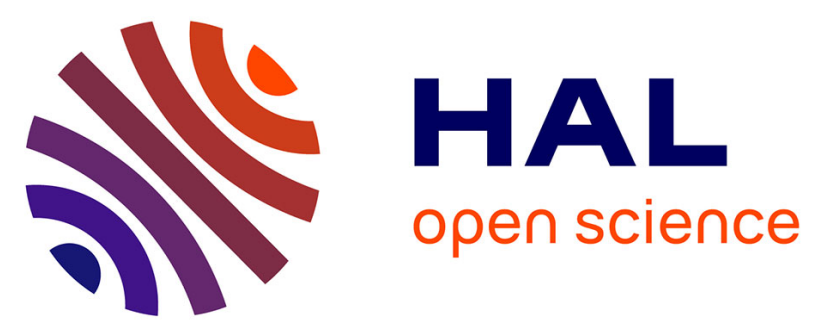

\title{
Connaissance, attitude et pratique des chiroptérologues vis à vis de la rage en Amazonie française
}

Brigitte Roman-Laverdure, Lucie Viavant, Philippe Abboud, Gaelle Walter, Alessia Melzani, Emilie Mosnier, Vincent Rufray, Guillaume Vesin, Félix

Djossou, Loïc Epelboin

\section{To cite this version:}

Brigitte Roman-Laverdure, Lucie Viavant, Philippe Abboud, Gaelle Walter, Alessia Melzani, et al.. Connaissance, attitude et pratique des chiroptérologues vis à vis de la rage en Amazonie française. 19 ème Journées Nationales d'Infectiologie (JNI), Jun 2018, Nantes, France. hal-02870321

\section{HAL Id: hal-02870321 https://hal.univ-guyane.fr/hal-02870321}

Submitted on 16 Jun 2020

HAL is a multi-disciplinary open access archive for the deposit and dissemination of scientific research documents, whether they are published or not. The documents may come from teaching and research institutions in France or abroad, or from public or private research centers.
L'archive ouverte pluridisciplinaire HAL, est destinée au dépôt et à la diffusion de documents scientifiques de niveau recherche, publiés ou non, émanant des établissements d'enseignement et de recherche français ou étrangers, des laboratoires publics ou privés. 


\section{Connaissance, attitude et pratique des chiroptérologues vis-à vis de la rage en Amazonie française}

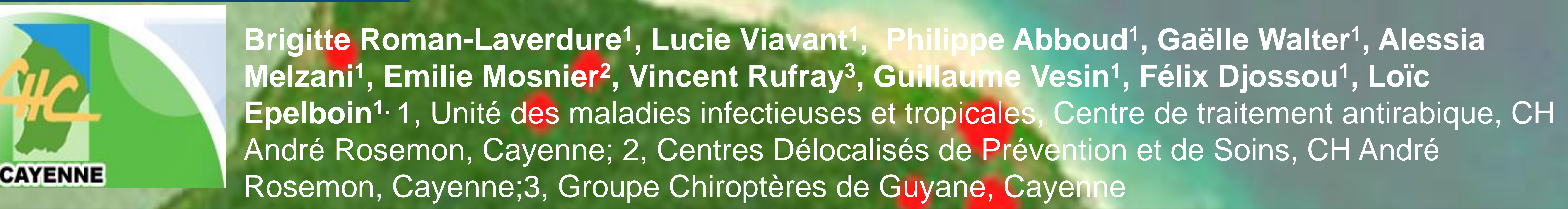

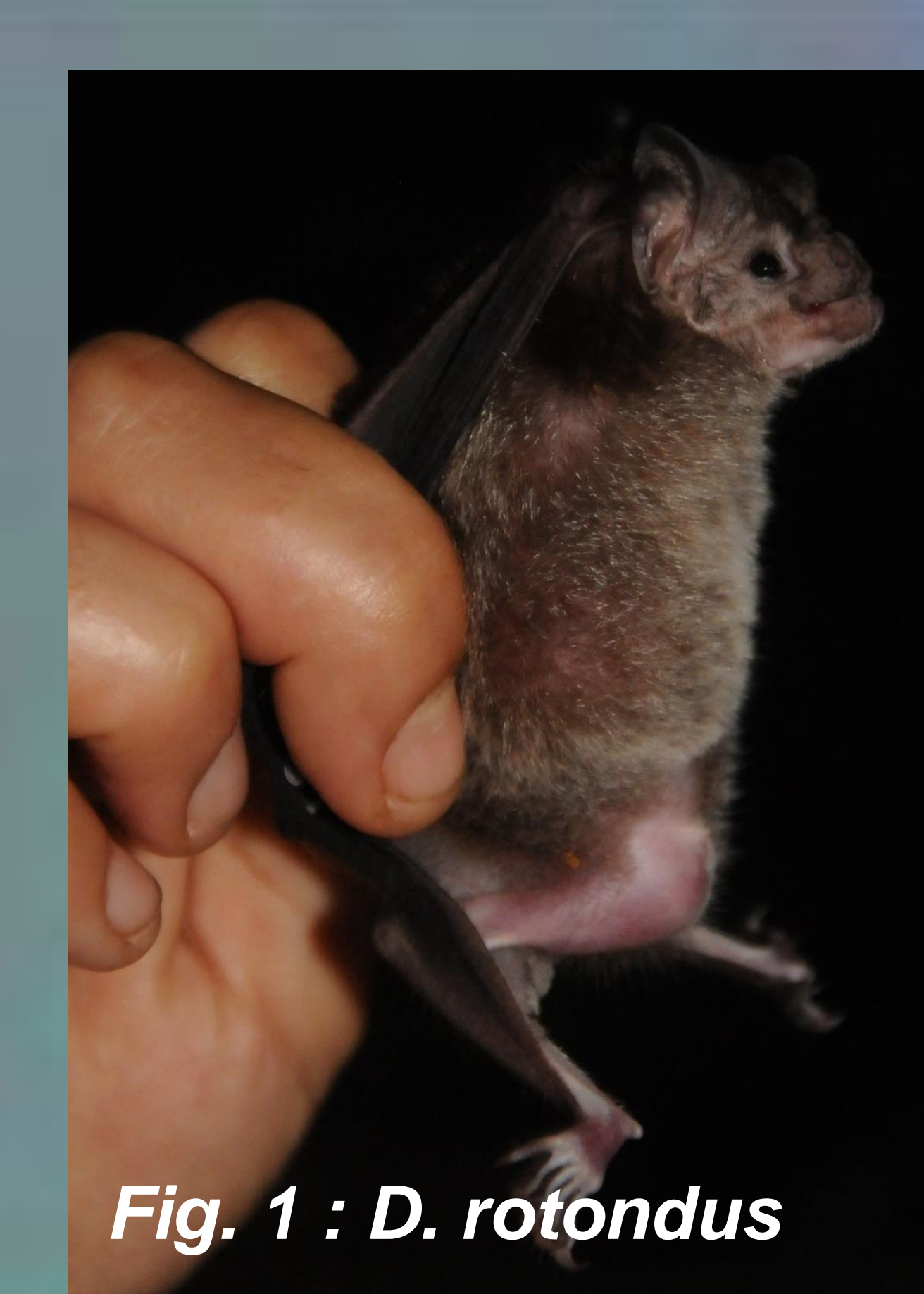

Introduction

La rage est une zoonose virale responsable de plus de 60000 décès par an dans le monde. Un seul cas de rage humaine avéré en Guyane en 2008. Le virus de la rage (genre Lyssavirus) est présent dans la salive de l'animal contaminé en fin de maladie.

La transmission se fait par morsure ou griffure par un animal contaminé ou léchage sur peau excoriée ou sur muqueuse.

En Guyane, il existe 2 principales espèces responsables de morsures à risque de transmission du virus de la rage et aboutissant à une prise en charge médicalisée : les chiens et les chiroptères, en particulier l'espèce hématophage Desmodus rotondus (figures 1 \& 4). Dernier cas de rage animal en 2015, diagnostiqué chez un chiot.

Plus de 100 espèces de chauves-souris existent en Guyane, et toutes potentiellement porteuses du virus, exposant les scientifiques et naturalistes étudiant les chauves-souris (chiroptérologues) à un risque répété lors des captures à visée scientifique (figures $2 \& 3$ ).

Objectif : Evaluer les connaissances de ces professionnels vis-à-vis du risque rabique et de sa prévention ainsi que leurs besoins en formation et informations émanant du Centre de Traitement Anti Rabique (CTAR).

\section{Matériels et méthode}

Etude descriptive, auto-questionnaire mis en ligne (Sondage Online). Période d'étude: Du 6/10/2017 au 6/11/2017.

Population d'étude : 60 membres de la liste de diffusion des chiroptérologues et passionnés de chauves-souris : "chiroguyane@yahoo.fr ».

Analyse rétrospective des données en rapports avec leurs pratique,

connaissances de la maladie, du traitement, de la vaccination antirabique et du suivi sérologique.

\section{Résultats}

\section{Description de la population}

- 20 personnes ont répondu au

questionnaire $(33 \%$ de la liste de

diffusion), dont 19 complètement.

- $65 \%$ étaient des hommes, $100 \%$

originaires d'Europe, $45 \%>40$

ans.

- $50 \%$ étaient en contact direct

avec des chauves-souris au moins

une fois par mois et $20 \%$ plusieurs

fois par semaine (cf. Figure $\left.n^{\circ} \mathbf{1}\right)$.

- $37 \%$ manipulaient parfois à

mains nues (cf. Figure ${ }^{\circ}{ }^{\circ}$ ).

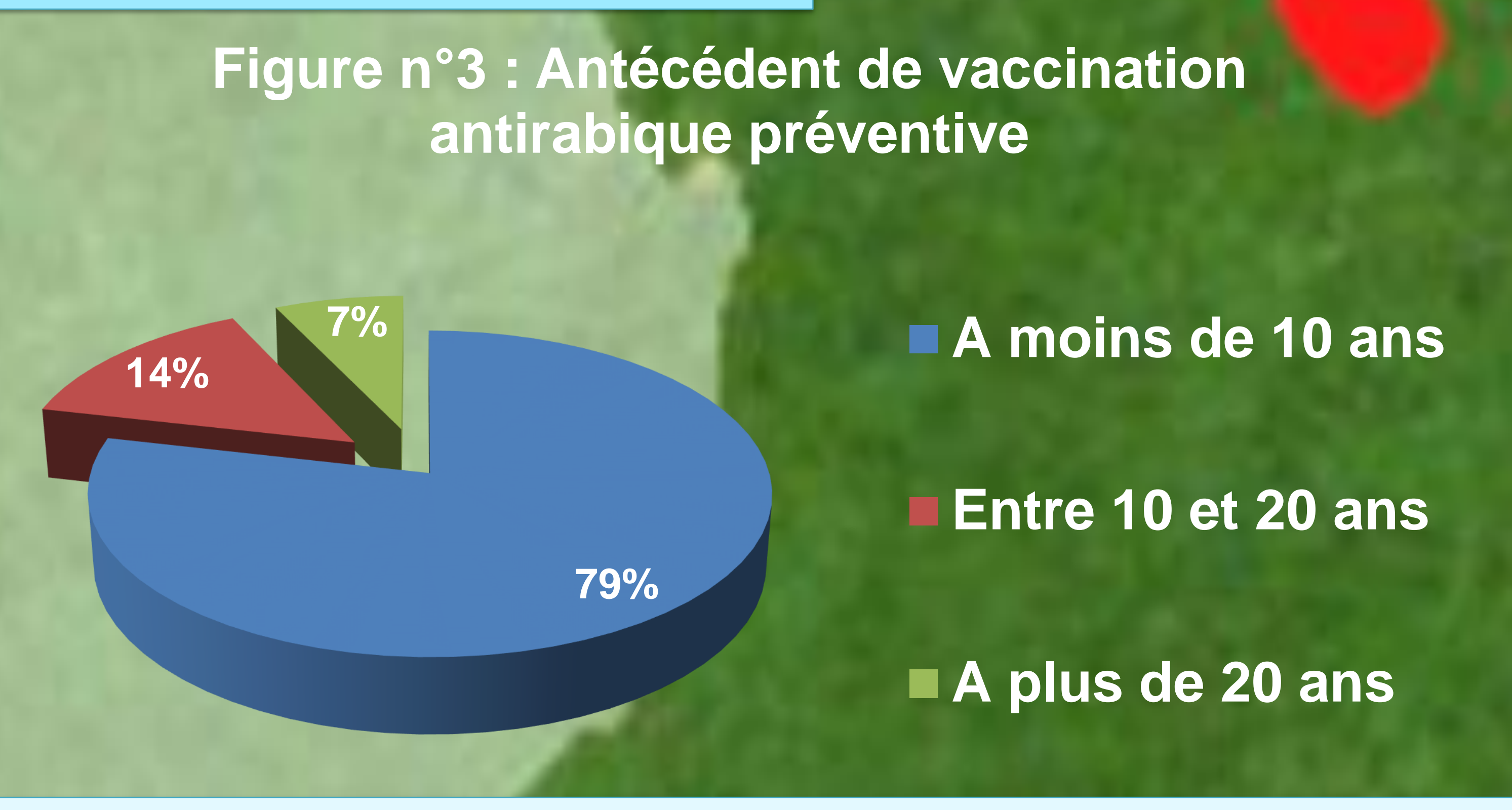

$>$ La primo vaccination antirabique et son suivi sérologique - $63 \%$ savaient que la vaccination antirabique préventive était recommandée chez les chiroptérologues.

- $79 \%$ avaient bénéficié de la vaccination antirabique préventive, et également $79 \%$ datant de moins de 10 ans (cf. Figure $n^{\circ} \mathbf{3}$ ). Seulement $7 \%$ pensent être à jour de leurs rappels.

- $56 \%$ disaient effectuer des contrôles d'anticorps mais seulement $37 \%$ savaient qu'elles s'effectuent chaque année (cf. Figure $n^{\circ} 4$ ). - 35\% savaient que la fréquence des contrôles dépend du degré du risque d'exposition (cf. Figure $n^{\circ} 5$ ).

- $63 \%$ savaient qu'une consultation au CTAR était nécessaire à chaque nouvelle exposition et $90 \%$ savaient que cette vaccination était nécessaire à leur activité

\section{Le CTAR et les chiroptérologues}

$63 \%$ pensaient être insuffisamment informés toutefois $79 \%$ souhaitaient plus d'informations.

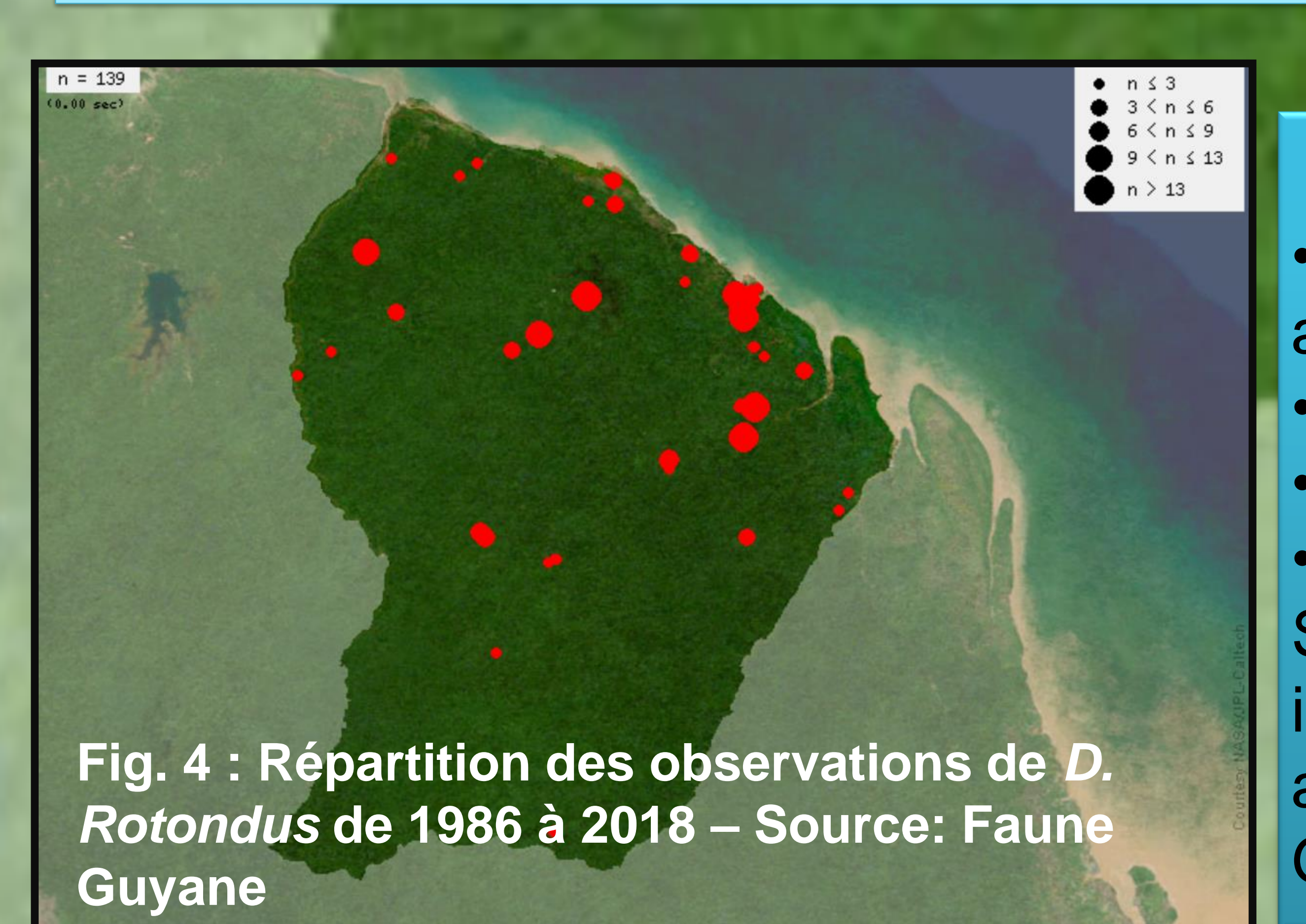

Discussion/Conclusion
- Chiroptérologues assez bien informés sur la rage et le risque inhérent à leur activité, en contraste
avec l'importance des prises de risque (manipulations à mains nues).
- Connaissances sur les possibilités thérapeutiques médiocres
- Couverture vaccinale déclarée et contrôles sérologiques insuffisants.
-Demandes et besoins en information importants.
Suite à cette étude, une des perspectives serait de développer l'une des mission du CTAR via des
informations en lignes, groupes de diffusion et Facebook, organisation de formations dans un cadre
associatif (Groupe Chiroptère de Guyane, Groupe d'étude et de Protection des Oiseaux de Guyane -
GEPOG...), les personnes concernées provenant de milieux professionnels hétérogènes.

\section{La rage et son traitement}

- $95 \%$ savaient que l'agent responsable de la rage est un virus.

- $75 \%$ savaient qu'il touche le cerveau et $35 \%$ les nerfs.

- 95\% savaient qu'il existe un traitement postexposition : composé de vaccins antirabiques seuls pour $31 \%$ et accompagnés d'immunoglobulines antirabiques pour $23 \%$.

- $84 \%$ savaient que la maladie est systématiquement mortelle une fois déclarée.

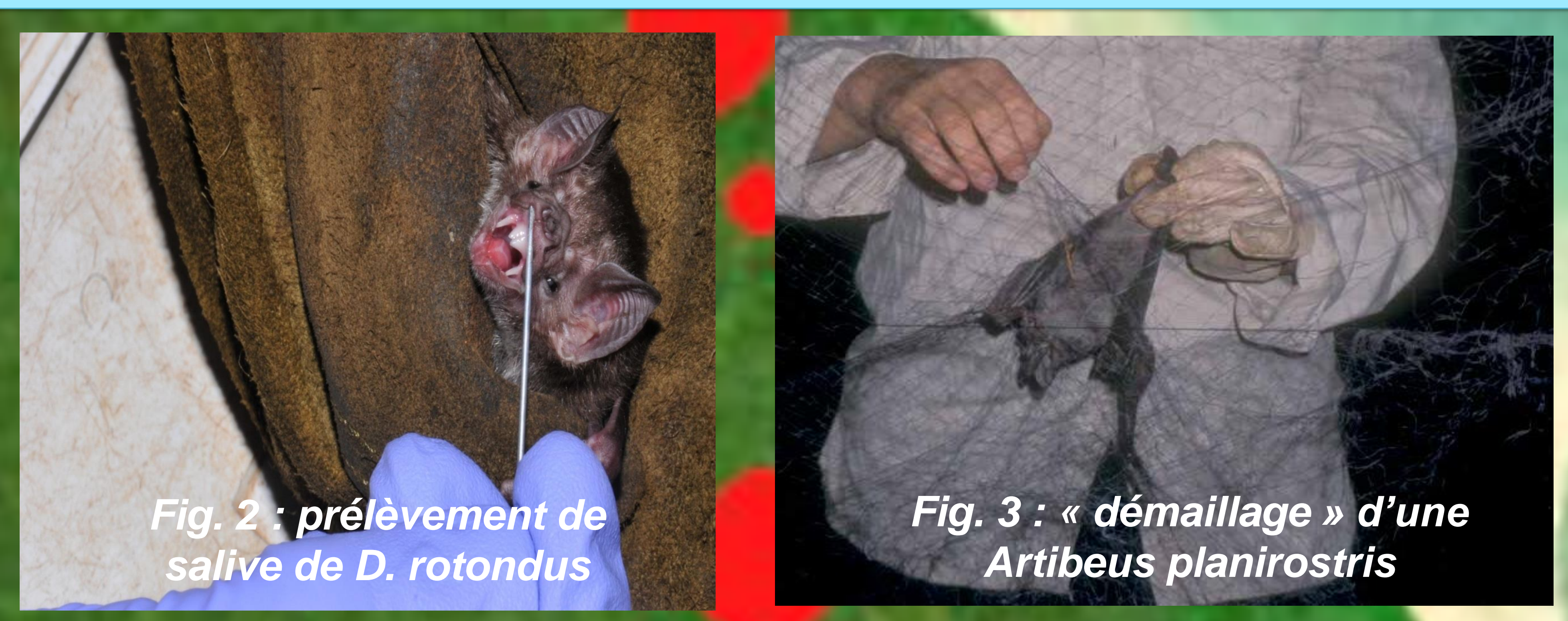

Figure $n^{\circ} 2$ : Mode de manipulations des chiroptères

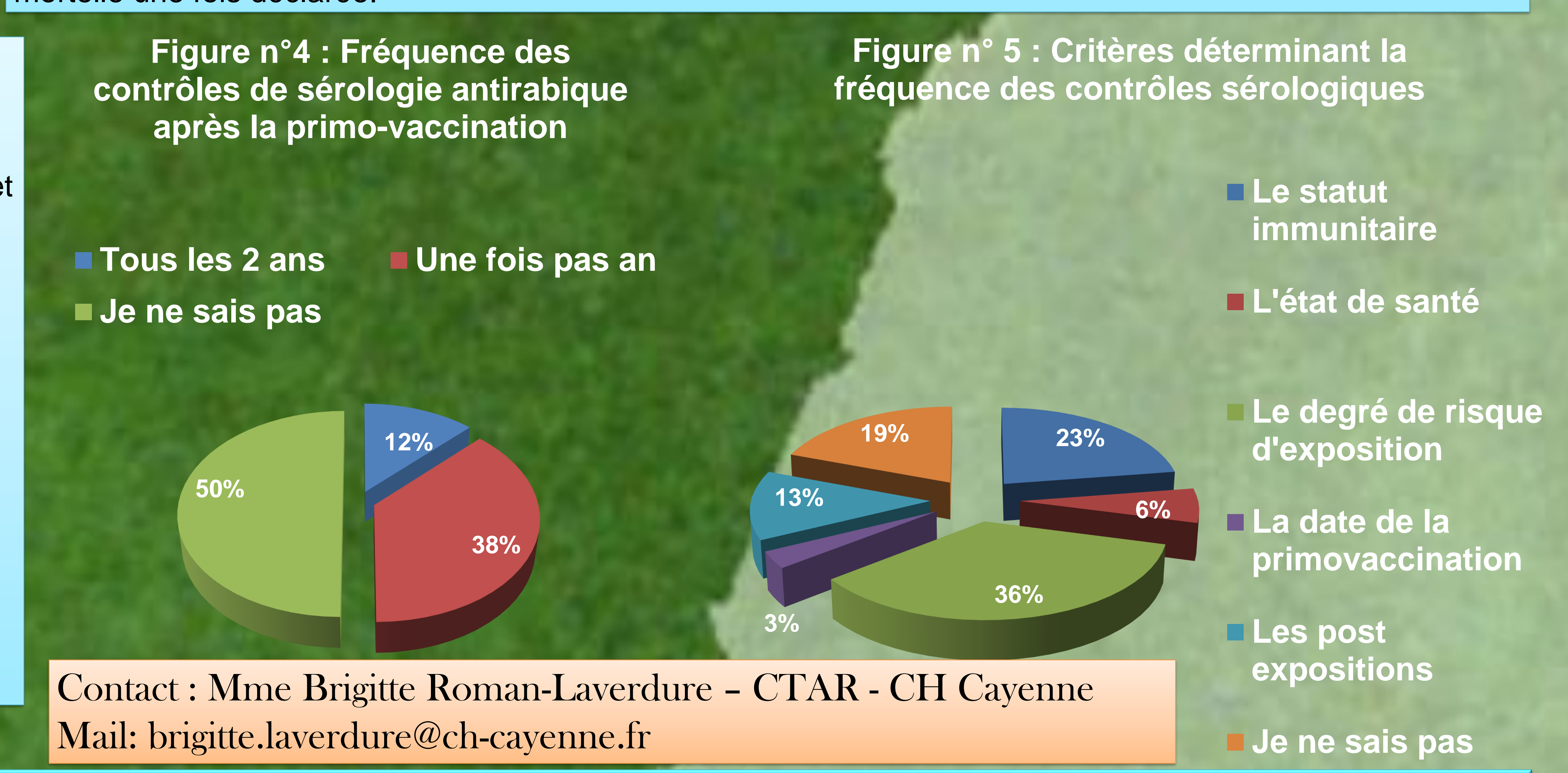
Guyane. de la rage en Guyane et 33\% pensaient qu'ils font partie des principaux vecteurs, en plus des chiens et chats.

- Seules 2 personnes ignoraient qu'il y avait déjà eu un cas de rage humaine (en 2008) en Guyane (11\%).

À mains nues

Avec un gant

Avec un

pochon

Avec de

gants e

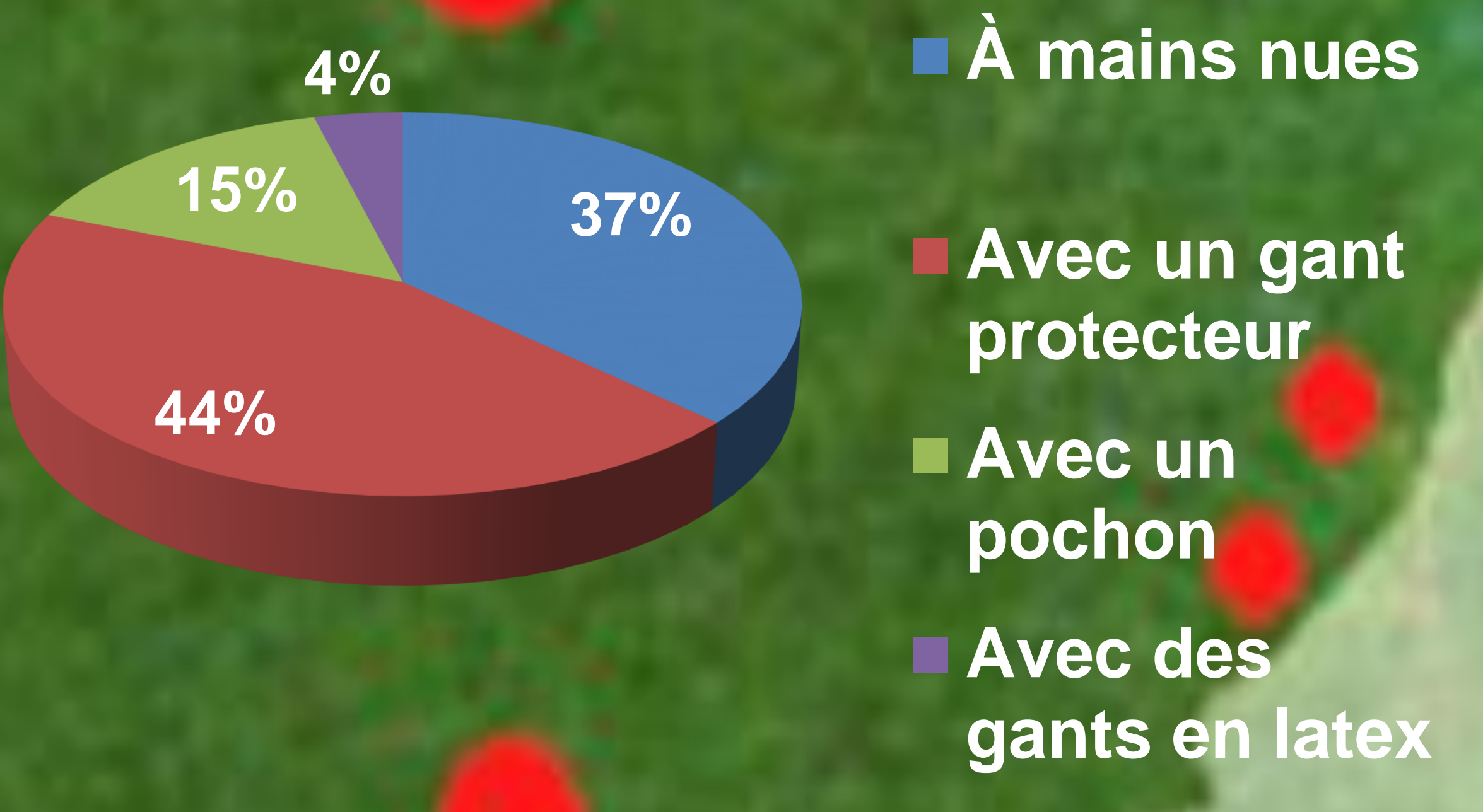

- $89 \%$ ne savaient pas que le génotype 1 RABV était

(1) 